\title{
BALANÇO SOBRE A LEI MARIA DA PENHA
}

\author{
Cecilia Maria Bacellar Sardenberg \\ Universidade Federal da Bahia \\ Miriam Pillar Grossi \\ Universidade Federal de Santa Catarina
}

Em novembro de 2004, há pouco mais de uma década, chegava ao Congresso Nacional, por intermédio da Secretaria Especial de Políticas para Mulheres (SPM), um projeto de lei de enfrentamento à violência conjugal, doméstica e familiar contra mulheres bastante ambicioso. Fruto de mais de três décadas de lutas dos movimentos feministas no país e, mais especificamente, dos esforços de um consórcio de organizações feministas em articulação com a SPM, o projeto respondia às recomendações tanto da Plataforma Política Feminista de 2002, quanto das Convenções CEDAW (Convenção sobre a Eliminação de Todas as Formas de Discriminação contra a Mulher) e Belém do Pará, assinadas e ratificadas pelo Estado Brasileiro.

De 2004 até agosto de 2006, quando foi finalmente sancionado pelo Presidente Lula da Silva como Lei 1 1.340, logo conhecida como Lei Maria da Penha (LMP), esse projeto mobilizou diferentes grupos dos movimentos de mulheres e feministas em todo o país, que pressionavam por mecanismos mais eficazes para prevenção à violência, proteção às mulheres e por medidas punitivas mais rigorosas para os agressores, de sorte a retirar o crime de violência contra as mulheres do rol dos crimes de menor potencial ofensivo.

Hoje, reconhecida por órgãos internacionais como modelo de legislação para o enfrentamento da violência doméstica contra mulheres (UNIFEM, 2009)', a LMP atendeu a essas demandas. Com efeito, tendo como objetivo maior criar "mecanismos para coibir e prevenir a violência doméstica e familiar contra a mulher" (artigo $1^{\circ}$ ), a Lei 11.340/2006 trouxe importantes inovações no ordenamento jurídico brasileiro na medida em que criou novas atribuições para as instituições da Polícia e da Justiça, além de comprometer na sua efetiva aplicabilidade outras instituições governamentais que, tradicionalmente, não participavam de ações de prevenção, atenção e enfretamento da violência de gênero. Dispondo, para tanto, sobre a criação de Juizados de Violência Doméstica e Familiar contra as Mulheres e definindo a necessidade de articulação de uma rede de atendimento e de medidas de assistência e proteção às mulheres em situação de violência doméstica

Copyright () 2015 by Revista Estudos Feministas.

${ }^{1}$ Disponível em: http:|lunifem.org/progress/2008 
e familiar, a LMP prescreve a necessidade de uma ação ampla e integrada na prevenção e no combate a essa violência por parte dos diversos níveis de Governo, do Poder Judiciário e de setores organizados da sociedade civil.

Por certo, tudo isso tem se traduzido em um grande marco político no sentido de avanços na luta contra a violência de gênero contra mulheres. Mas, é preciso ressaltar que os desafios postos para garantir a implementação da Lei, nos moldes esperados, não têm sido poucos e os resultados nem sempre têm se mostrado satisfatórios (OBSERVE, 2009, 2010, 201 1). ${ }^{2}$ Ademais, tal como previsto na própria Lei Maria da Penha, é preciso desenvolver mecanismos de monitoramento sistemático, também por parte da sociedade civil, incluindose aí estudos e pesquisas que possam avaliar sua implementação e aplicação a partir de distintas perspectivas e abordagens, oferecendo subsídios para as a eficácia das políticas.

O dossiê aqui apresentado tem por objetivo mais amplo caminhar nessa direção, abrindo espaço para reflexões sobre esses desafios e resultados, fazendo, por assim dizer, um "balanço" da primeira década da Lei Maria da Penha, considerando a data de sua formulação. Para tanto, reunimos artigos de pesquisadoras e pesquisadores que vêm trabalhando com essa temática já há algum tempo e que se debruçam, aqui, sobre aspectos diferentes da aplicabilidade da Lei.

Iniciamos com as reflexões de Lourdes Maria Bandeira e Tânia Mara Campos de Almeida, no artigo Vinte anos da Convenção de Belém do Pará e a Lei Maria da Penha, onde são delineados os caminhos traçados na construção de parâmetros e diretrizes de âmbito internacional para o enfrentamento da violência de gênero contra mulheres, com ênfase na Convenção Interamericana para Prevenir, Punir e Erradicar a Violência Contra a Mulher (Convenção de Belém do Pará), de 1994, que se constituiu como o modelo base para a formulação da Lei Maria da Penha. As autoras discutem os princípios fundamentais dessa Convenção e como se refletem na Lei Maria da Penha, destacando a "relevância da Convenção", por "se constituir pioneira e ainda se manter nesse lugar de vanguarda simbólica e jurídica internacional em âmbito supra continental". E ao se voltarem para uma avaliação da eficácia da Lei Maria da Penha em, de fato, corresponder a esses princípios, argumentam ser necessário distinguirmos sua "eficácia social" da "eficácia jurídica", indicando que, enquanto a primeira vem se efetivando, gradativamente, desde que foi sancionada, a "jurídica" ainda deixa a desejar, fazedo-se "necessário a criação de outro modelo cultural-político no âmbito do Poder Judiciário, em consonância com o espírito da Convenção de Belém do Pará, que abriga a LMP”.

A conclusões semelhantes chega o artigo de Carmen Hein de Campos, A CPMI da Violência contra a Mulher e a implementação da Lei Maria da Penha, que analisa os resultados da Comissão Parlamentar Mista de Inquérito da Violência contra a Mulher criada pelo Congresso Nacional Brasileiro, em 2012, para avaliar a aplicação da Lei Maria da Penha. Segundo relata a autora - que participou desse processo como Assessora da Comissão--, a investigação indicou que, no país, as políticas de enfrentamento à violência contra mulheres ainda se mostram bastante frágeis. A Comissão detectou, também, uma série de obstáculos que se interpõem na implementação da Lei Maria da Penha, destacando dentre eles: "a) a fragilidade da rede especializada de serviços de atendimento às mulheres em situação de violência; b) o reduzido número de juizados especializados de violência doméstica e familiar contra a mulher; c) o descumprimento da decisão do Supremo Tribunal Federal que proíbe a aplicação da suspensão condicional do processo; d) a resistência de operadores/as do direito em entender a proposta da nova lei e romper com a lógica familista; e) o insuficiente orçamento para o desenvolvimento e a manutenção das

${ }^{2}$ Disponível em: www.observe.ufba.br 
políticas públicas de enfrentamento à violência contra mulheres". Em especial, as considerações finais do artigo voltam-se para a precariedade dos orçamentos destinados, não só ao enfrentamento da violência, mas às políticas públicas para mulheres, de um modo geral, argumentando em favor da construção de uma política orçamentária de gênero. Chamam atenção, também, para a necessidade de uma "nova compreensão jurídica", bem como de mecanismos que possam contribuir para uma melhor "articulação entre os poderes públicos".

Note-se que essa é também uma das considerações trazidas por Wânia Pasinato no artigo, Oito anos de Lei Maria da Penha. Entre avanços, obstáculos e desafios. Reconhecendo os avanços registrados, bem como os diferentes problemas que vêm sendo identificados na aplicação dessa Lei, o artigo em questão volta-se, sobretudo, para a análise de um atendimento em rede. Segundo observa a autora, na medida em que a Lei define um "conjunto de ações de prevenção, assistência, proteção e garantia de direitos das mulheres e para o combate à impunidade de seus agressores," implica em uma política intersetorial e multidisciplinar "cuja concretização deverá resultar da articulação entre os poderes Legislativo, Judiciário e Executivo" em todos níveis, ou seja, um trabalho em rede. Observa a autora, contudo, que o atendimento nessas redes, além de precário, ainda revela uma grande desarticulação entre os serviços: são também precariamente conectados, funcionando parte deles em bases de relações individuais e de favores. Tornase, pois, necessário institucionalizar essas redes, criando instâncias de articulação, forjadas com o foco nas "mulheres em situação de violência", considerando-as como "sujeitos políticos e capazes de transformar a situação em que se encontram a partir do acesso aos direitos que são universais, inalienáveis e indivisíveis".

Os três artigos que se seguem são estudos de caso que nos permitem vislumbrar, mais de perto, como os obstáculos e as limitações na aplicação da LMP delineados, desenrolam-se no cotidiano desses serviços. Márcia Santana Tavares traz a experiência de pesquisa realizada em 2012, utilizando rodas de conversas com mulheres, que acionaram as redes de atendimento a mulheres em situação de violência doméstica e familiar, cujos relatos subsidiaram o dossiê enviado à CPMI do Congresso Nacional, referente à aplicação da LMP na Bahia. Relatos que traduziram sentimentos de descrença, desencantamento e impotência das mulheres participantes da pesquisa diante do descumprimento da LMP em serviços de atendimento acionados por elas, e pelas formas como foram tratadas, sentindo-se muitas vezes desrespeitadas e desassistidas, por profissionais que ainda tratavam as violências de gênero como questões da esfera privada.

Partindo de pesquisa etnográfica, realizada em comarca de uma cidade do Sul do Brasil (2010-2011) a respeito do conceito de violências psicológicas previstas na LPM, Isadora Vier Machado e Miriam Pillar Grossi propuseram-se a avaliar as formas como este conceito é operacionalizado por membros do Ministério Público. Não existindo na época da pesquisa uma vara especializada para atendimento dos casos enquadrados na LPM, esse era feito nas Varas Criminais e por uma promotoria especializada. Houve, por parte da promotora e dos promotores entrevistados no Ministério Público, um reconhecimento explícito da função estratégica do conceito de natureza jurídico-política, embora sua instrumentalização passasse pela necessidade de enquadramento legal. As autoras concluíram que a compreensão do conceito, nas formas como é operacionalizado, mostra que a discussão teórica é fundamental no processo de implementação da LMP para aperfeiçoar as estratégias extrajurídicas que o diploma legal esboça e para resgatar elementos da história da Lei, em relação às aspirações das instâncias envolvidas em sua elaboração. 
Com pesquisa sobre os serviços prestados por diferentes instituições de atendimento a mulheres em situação de violência, Cecília MacDowell Santos analisa a constituição de redes de enfrentamento à violência contra mulheres na cidade de São Paulo (2010-2013). Denunciando a existência de um paralelismo jurídico-político do Estado em relação ao enfrentamento da violência contra as mulheres entre os setores brasileiros da assistência social e das políticas para as mulheres, a autora analisa o predomínio de concepções familistas professadas por agentes de instituições de atendimento, a existência de ações guiadas por perspectivas feministas, bem como posturas que privilegiam concepções de gênero e concepções interseccionais de gênero/classe/raça, em outras organizações pesquisadas. A autora acredita que é preciso conhecer de perto cada organização, sua história, limitações e oportunidades institucionais e políticas, pois são esses os fatores que influenciam as dinâmicas das abordagens no atendimento à violência contra as mulheres nas redes estudadas.

Por fim, a pesquisa de Regina Ingrid Bragagnolo, Mara Coelho de Souza Lago e Theophilos Rifiotis, em comarca da Região Metropolitana de Florianópolis, Sul do Brasil, em 2008-2010 quando ainda não haviam sido criados em Santa Catarina os Juizados de Violência Doméstica e Familiar contra a Mulher, previstos na LMP, foi realizada com operadores e operadoras de direito de uma Vara Criminal em que eram acolhidos os casos de violência contra a mulher. As entrevistas, observações de audiências e análises de processos penais, mostraram que as práticas dos/as operadores/as de direito em relação aos casos pertinentes à LMP estiveram muito orientadas pelos estilos pessoais dos/as juízes/as e de seus valores morais na condução de audiências de ratificação, frustrando em muitos casos, as expectativas feministas que levaram à criação da Lei 11.340/2006.

Os textos aqui apresentados trazem, portanto, um amplo leque de abordagens sobre a aplicação da Lei Maria da Penha e os impactos que trouxe para o campo dos estudos sobre violências contra as mulheres no Brasil. Proporcionam uma importante contribuição para o campo de estudos acadêmicos que se debruçam sobre as relações entre gênero e violência e devem, também, ser lidos por gestores públicos do campo jurídico, da segurança pública e dos direitos humanos. Sem dúvida, os resultados e as questões que trazem poderão contribuir para a implementação de políticas públicas, a melhoria nos serviços já existentes, e marcar o ponto de partida para novas investigações. 